\title{
Technology of social and emotional learning as a tool for preparing students for inclusive education
}

\author{
T.Y. Chetverikova ${ }^{1 *}, O . S$. Kuzmina ${ }^{2}$, and $O . Y u$. Sinevich $^{3}$ \\ 1 Omsk State Pedagogical University, Omsk, Russia \\ ${ }^{2}$ Omsk State Pedagogical University, Omsk, Russia \\ ${ }^{3}$ Omsk State Pedagogical University, Omsk, Russia
}

\begin{abstract}
The article presents a study devoted to the use of technology social-emotional learning in the preparation of graduate students for professional activity in the system of inclusive education. The review of scientific achievements in the development of social skills and emotional intelligence in students of different age groups is carried out. The specifics of the formation of social and emotional skills in students who master the phenomenology of inclusive education in theoretical and practical aspects are determined. The article describes the mechanisms for implementing the technology of social and emotional learning in preparing future teachers to work in an inclusive environment, including living in a social and educational situation, evaluating and managing their own feelings, and understanding the feelings of other people. The expected result of using the proposed technology is recorded in the form of the ability of future specialists to solve professional problems in the field of inclusive education, as well as their possession of a value attitude to inclusive culture and its subjects, including people with disabilities.
\end{abstract}

\section{A problem statement}

The idea of inclusive education is being actively developed and implemented in the world community. This fact is determined by various reasons. These include a change in the educational paradigm associated with the development of humanistic trends in the education and upbringing of the younger generation; the formation of a social request on behalf of parents as legal representatives of children with limited health opportunities (LHO); changes in legislation and state policy in the field of education.

In Russian Federation, inclusive education at the state level is interpreted as equal access to education for all students, including those with LHO, taking into account the diversity of special educational needs and individual opportunities. In the context of our research, inclusion is considered as a social and educational model, in which joint training of persons with normative and impaired development is carried out in General-type

* Corresponding author: ipcs-profped@yandex.ru 
institutions, where all the necessary conditions are created for a comfortable stay, quality education, and mastery of social competencies for all groups of students.

An important condition for ensuring that students with LHO receive quality and affordable education is the professional competence of teachers who implement the ideas of inclusion in direct practical activities.

In the research of E.V. Bulavkina and T.V. Timokhina, it is noted that in the system of teacher training there are contradictions between modern requirements for the development of inclusive education and the lack of fully functioning mechanisms for such training. The authors note that the result of such training, which is consistent with the state educational policy and social demands, is expressed in the following: the teacher is personally and professionally focused on including a child with LHO in the General education space, correcting their individual educational and socio-personal problems, and is also able to provide qualified assistance to the student in mastering the educational program and social adaptation [1].

V. Gyurova and V.P. Zeleeva insist that a new generation teacher should have not only versatile skills, competence in terms of ownership of the subject content of the course taught, but also be able to create a social environment during the educational process that provides emotional comfort for all participants in the educational process [2]. This position deserves attention. It shows the need not only theoretically and practically to prepare the teacher for inclusive practice, but also the importance of ensuring his personal readiness to implement inclusive practice, which will eliminate cases of formal association of students with normal and impaired development (pseudo-inclusion), create conditions for full interaction of these groups of students.

In the works of E.S. Zair-Bek, we find confirmation of this position and an indication of the need to create a social and emotional background in the system of training future teachers, which contributes to the formation of students ' learning stability, self-regulation, self-effectiveness, communication, and conflict-free relationships [3]. The author points out the fact that these qualities of the future teacher contribute to the formation of his behavioral manifestations as a professional. In the absence of sufficient attention to this issue, a University graduate may be unprepared to successfully solve not only complex, but also traditional tasks that they are called upon to solve when it is necessary to implement inclusive practices.

The above points out that there is a problem that requires a comprehensive and systematic study. It is the need of search and testing technology of preparation of future teachers for working in conditions of inclusion, given the state of educational policy, scientific advances, expectations of society and enculturation capacity (in the current system of values, experience, traditions), special needs of students with LHO, as well as a number of other factors that are related in semantic terms listed above. Accordingly, the simulated technology, on the one hand, should provide students with the opportunity to master the relevant professional competencies in the field of special education. On the other hand, the result of the practical implementation of this technology should be the personal and emotional-value readiness of future professionals to solve their professional tasks in an inclusive environment.

\subsection{The objective of the work}

Studying various approaches to training a future teacher who is capable of constructive solutions to traditional and problematic issues of professional content, we can identify a number of significant vectors that have been formed as a result of prolonged scientific research. First, within the framework of such training, it is necessary to teach future teachers to solve professional and educational tasks aimed at developing their ability to 
actually teach (E.S. Zair-Bek) [3; 4]. In the context of our research, this suggests that students of a pedagogical University should purposefully develop professional competence in the field of organizing joint education of children with normal and impaired development.

Second, students ' education should be focused on developing their social skills. N.A. Gorokhovskaya's research notes that such skills include the ability to adapt in the professional sphere, activity and leadership, self-management, and teamwork skills [5]. With regard to the problem of preparing a future teacher for inclusive practice, we can state the following: in order for students to master these skills in the higher education system, it is necessary to create a social space that is close to real pedagogical practice. This will not only allow students to demonstrate possible models of interaction between participants in educational relations in the context of inclusion, but also teach them to find the most optimal ways to solve problematic issues that arise in the professional activity of the specialist involved in it.

The next vector is a value-oriented orientation in the education of higher school students. Thus, N.V. Simonov notes the need to develop future specialists ' social and professional competence, which consists of the following components: possession of professional functions; social and communicative, managerial, methodological and sociotechnological knowledge and experience, which together contributes to the awareness and acceptance of the value and meaning of the future profession [6]. The results of scientific research by N.V. Simonov allow us to state that when determining the strategy of preparing students for inclusive education, the value-semantic orientation to the philosophy of inclusion becomes one of the most significant. This allows students to adequately understand the essence of the phenomenon being mastered in theoretical terms and the conditions for implementing inclusion in practice.

In our opinion, the solution to this problem in preparing future teachers to implement the ideas of inclusion can be the technology of social and emotional learning. In foreign and domestic research, the technology of social and emotional learning is given a leading role (O.A. Antropova, R.G. Apresyan, M.A. Ariyan, E.M. Bim, N.B. Golubeva, D. Goleman, A.V. Kiryakova, M.N. Kozhevnikova, V.P. Musina, L.M. Naimushina, Y.V. Shcherbina, etc.).

Let's consider the level of knowledge of the issue concerning the specifics of the use of social and emotional learning technology in the educational process.

The initial point of development of social and emotional learning idea is considered to be the works of D. Goleman, in which he reveals and strongly justifies the importance of emotional intelligence for the formation of thinking and the formation of a subject's value attitude to the world [7]. A wide range of scientific research results of the scientist allowed us to record that the analysis of personal emotions by a person organizes the complex work of the brain, contributes to the mapping of human feelings and the formation of adequate responses to life situations. This scientific approach became the basis for the emergence of social and emotional learning, and made it possible to consider it as an innovative program or technology.

Scientific and methodological guidelines for using the technology of social and emotional learning when working with preschool children are revealed in the research of E.M. beam, R. Crowe, and M. Cooper [8]. Scientists point to the axiomatic position that the biological development of a child is closely related to the socio-emotional aspect of his life practice. The authors point out the need for such an organization of the educational process and the socio-educational environment, in which all pedagogical actions and activities will contribute to the close connection of the biological and socio-emotional components, starting from early childhood. 
Social and emotional learning is considered by O.A. Antropova as a new direction in the development of pedagogical science and school practice [9]. Thus, the author points out that social and emotional learning contributes to the formation of students ' social and academic (in all areas of educational activity) competence. Social and emotional learning provides an opportunity for children to develop the ability to manage their own emotions, understand the experiences of others, make decisions and establish positive interaction with others. O.A. Antropova reveals the main directions that reflect the context of social and emotional learning. These include self - awareness (working on self-esteem and awareness of one's own emotions), self-management (working on mental balance and setting goals and learning plans), social consciousness (developing empathy for others), constructive interaction with the social environment (ability to resolve interpersonal conflicts, support healthy social relationships), and responsibility in decision-making (making informed decisions and understanding their consequences). The researcher focuses on the fact that the technology of social and emotional learning allows for a high social and educational effect even when it is used in higher education-in connection with the training of teachers.

In the works of L.R. Mukhametgalina, there are indications of the need to apply the technology of social and emotional learning when working with adolescents [10]. The researcher provides arguments in defense of the provisions that the technology of social and emotional learning is aimed, on the one hand, at developing values-requirements in adolescents. On the other hand, the use of such technology contributes to the cognitive and emotional development of adolescents.

In the context of our research, the works of N.B. Golubeva and V.P. Musina are of considerable interest $[11 ; 12]$. In particular, the article N.B. Golubeva notes: use of socialemotional learning technology in higher schools has a beneficial effect due to the fact that links the affective and cognitive side of the learning process; provides formation of students ' professional qualities, which simultaneously contribute to his formation as a member of society and bearer of emotions [11].

V.P. Musina presents data from a comparative study that reflects the state of social intelligence in first-and final-year students [12]. The scientist identified significant relationships between social, emotional intelligence and social communicative competence of Students. V.P. Musina defined the conditions for the development of social intelligence. Among them, it includes the reflexive nature of learning, orientation to the awareness of the personal meaning of learning, the solution of communicative tasks at the subject-subject level in the course of practical classes, the inclusion of students in the process of interaction with other people.

The technology of social and emotional learning is also of interest for the defectological science and practice of education of children and adolescents with disabilities - different nosological groups. The article by Y.V. Shcherbina, E.S. Rakhimova, and T.V. Volkodav notes the high potential of this technology in forming self-esteem of students with disabilities, reducing aggressive and antisocial behavior, and reducing emotional disorders and depressive symptoms [13]. At the same time, the authors rightly point out the need for additional research aimed at establishing the impact of socio-emotional learning on mental health and social integration of students with LHO.

The educational effect of the use of social and emotional training is noted in the research of R.G. Apresyan [14] in connection with the coverage of the concept of social and emotional training and the tasks of moral education. The author asserts that social and emotional learning appears as a means of forming specific values in children, a tool for developing the ability to understand values in cognitive and social terms, as well as to act in accordance with them.

On the potential use of technology social-emotional learning to address problems of forming basic educational and professional knowledge, as well as for further a full life in 
the modern world noted in A.V. Kiryakova, M.K. Ergaliev, S.V. Zaitseva, A.K. Suleymanova [15]. The authors note that the skills of building relationships, making decisions, managing emotions, empathy, and achieving goals form social and emotional learning. These authors reveal approaches that promote the harmonious development of the individual's cognitive and emotional abilities. The researchers point to the need to introduce a philosophical approach to the educational process for a balanced formation of these abilities in students.

The article by L.M. Naimushina provides methodological foundations for social and emotional learning, including the ideas of unity of affective and intellectual processes by L.S. Vygotsky, the idea of emotions as regulators of mental activity by S.L. Rubinstein, and the concept of the influence of emotions on cognition by J.S. Vygotsky. Meyer and P. Solovey etc. [16].

M.N. Kozhevnikova, in turn, systematized domestic approaches to understanding such a phenomenon as "social and emotional learning" and revealed its deep value value for the development of students ' abilities to skillfully handle themselves, empathize with others, and the ability to communicate constructively [17]. For our research, this scientific vision of the problem is of great interest, since it reflects the main purpose of preparing students for inclusive education - the formation of a value attitude towards people with LHO.

\section{Materials and the results of the research}

The analysis of scientific research in the field of applying the technology of social and emotional learning allowed us to determine the purpose and objectives of our research.

The purpose of the study was to study the possibility of using the technology of social and emotional learning to optimize the process of preparing future teachers for inclusive education. As the final result of training, the complex of knowledge, skills and abilities formed by students was considered, namely:

- the understanding the philosophy of inclusive education in general and the emotional and value attitude towards people with LHO in particular;

- the ability to choose the most optimal ways to organize joint activities of children with normative and impaired development;

- the skills of building active and constructive interaction of all participants in the educational process;

- the ability to make informed decisions when organizing co-education of normatively developing children and their peers with LHO;

- the willingness to manage their own professional development on issues of inclusive education.

The research objectives included the following:

1) the development of a program of initial diagnostics aimed at identifying the level of readiness of future teachers for inclusive education;

2) the designing of logic of applying the technology of social and emotional learning in the context of preparing students for inclusive education;

3 ) the assessment of the impact of social and emotional learning technology on the preparation of future teachers for inclusive education.

The main methods of the study, which participants were students of the pedagogical University, were the following: survey, pedagogical observation, professional problem solving, expert evaluation of products of activity in the process of immersion in a professionally-oriented environment and the method of social and educational projects. The study was conducted over two years. The number of participants in the study is 156 fourth year students. Students are trained in various programs of "Special (defectological) education", namely: "Speech therapy", "Preschool defectology", "Special psychology". 
During the initial diagnostics, it was revealed that students who master the theory and practice of inclusive education are mostly familiar with its basic provisions and mainly in the theoretical aspect, which corresponds to the average and advanced levels. The practical and personal aspect of readiness does not exceed the average level, and its dominant indicator corresponds to the initial level. Students are familiar with the specifics of organizing an inclusive space, techniques for implementing educational and rehabilitation activities. At the same time, students are not ready to present a complete and reasonable algorithm that reflects the true inclusion of a child with LHO in the environment of normotypic peers; methods for developing social interactions of all participants in the educational process. Choosing a particular educational tactic, students do not calculate the possible risks associated with the implementation of inclusive practice of a particular student: taking into account his / her psychophysical capabilities and limitations due to the existing disorder; the state of social competencies, experience of interaction with healthy peers. When determining the essence of educational and correctional work in the system of inclusive education, students mainly focus on the specifics due to the content of the profile they master, leaving out a wide range of professional actions and issues that determine the success of integrating students with disabilities into a complex system of socially-personal and educational relations.

The results of the study were the basis for determining methodological guidelines that reflect the specifics of using the technology of social and emotional learning in the higher education system to prepare future teachers-defectologists to work in conditions of inclusion.

The developed methodological bases that reflect the specifics of implementing the technology of social and emotional learning for preparing future teachers-defectologists to work in conditions of inclusion can be presented in the form of the following conclusions.

1. In the process of preparing students for inclusive education, conditions should be created both for their cognitive development (acquaintance with the essence of inclusive education, special educational needs of children with LHO, technologies of correctional and pedagogical influence) and for the emotional development of students (immersion in a professionally oriented environment, analysis of the emotional context of professional activity, construction of value goals and plans, making responsible decisions based on the results of the analysis of the proposed problem situation, highlighting the value meanings of the predicted and implemented actions of a specialist).

2. Any activity of students (educational, design, technological, etc.) should be based on the fundamental values of the philosophy of inclusive education. In the process of direct activity, future teachers should purposefully develop social and emotional skills related to modeling adequate behavioral responses of a specialist, productive approaches to solving problem situations.

3. The development of students ' social and emotional skills that ensure readiness for inclusive practice should be carried out through educational modeling of practical activities, so that students can master an inclusive culture, ways of organizing an inclusive environment that meets the interests and needs of all participants in the educational process.

4. When forming future teachers ' social and emotional skills, it is necessary to use the environment of educational organizations involved in inclusive education in order to immerse students in a professionally oriented environment. Considering immersion in a professionally oriented environment as a mechanism for developing students ' adaptive mechanisms and socially significant skills, we understand that in parallel with this, the future teacher develops their own capabilities based on a conscious choice of the method of social and professional behavior in the process of mastering various social roles (S.V. Shcherbakov) [18]. 
The technology of social and emotional learning in preparing students for inclusive education is considered by us as a special way of organizing joint activities of students (students) and the teacher (teacher), which allows forming self-awareness, selfmanagement, social consciousness, skills of constructive interaction with the social environment, responsibility for professional decisions.

Approaches to the implementation of this technology can be presented in the form of successive stages that reflect the main content of higher school students ' activities:

- the immersion in a professionally oriented environment (familiarity with its organization, management mechanisms, socio-cultural traditions);

- the analysis of the social and emotional context of the inclusive education system in general and specific inclusive practices in particular;

- designing value goals and plans that ensure the creation of an inclusive environment that meets social needs, expectations of participants in the educational process, opportunities and special needs of students with LHO;

- making responsible decisions based on the analysis of problem situations that arise in inclusive practice;

- the identification of value meanings in the activities of a specialist (in all its areas) who implements inclusive practice.

As a result of implementing the presented technology, students develop social and emotional skills that correspond to five key areas: self-awareness, social awareness, selfmanagement, relationship management, and responsible decision-making.

Here are some examples that illustrate the practical use of social and emotional learning technology.

At the stage of immersion of students in a professionally oriented environment, they live their own emotions and feelings while performing various activities, which include case studies, the method of ethical dilemmas, the method of affective induction, the method of social and problem situations, visual methods and role-playing games, social and educational projects.

The method of affective induction used in the analysis of trends in the development of inclusive education allows students to establish the interdependence between the actions of teachers and the real consequences for inclusive practice. This encourages future teachers to understand the role of the specialist and his decisions in the design and consolidation of both positive and negative practices of co-education of children with normative and impaired development.

The use of the method of ethical dilemmas, which consists in the situation of choosing one of two mutually exclusive solutions (which are not perfect from a moral point of view), contributes to the formation of students ' strategies of behavior in a situation of high uncertainty; skills of adequate and effective relationship management; actualization of professional and social responsibility for decisions and actions taken.

In the process of solving case assignments, simulation outputs from the social and problem situations, students develop positive attitude to inclusive practice and values of inclusion, practiced technicians provide specialized assistance to child with LHO integrated into their non-disabled peers: given his special needs, the structure of the violation, the experience of socio-communicative interaction with others. In role-playing games and social and educational projects, a specialist develops the necessary skills for social interaction, flexibility, and the ability to cooperate with associates.

A number of quite effective, in our opinion, methods of social and emotional learning are presented in the work of M.A. Ariyan [19]. Thus, it is advisable for students to perform various communicative tasks that stimulate the emergence of a particular emotional state, leading the student to the need to Express this state, establish and maintain emotional contact with the interlocutor, and predict the emotional reaction of the interaction partner. 
The proposed technology of social and emotional learning acts as a fairly flexible tool for preparing students for inclusive education, and therefore can be saturated with various types of activities, organizational forms of work with students that do not contradict its essence and purpose.

\section{Conclusions}

The technology of social and emotional learning is one of the tools for preparing high school students for inclusive education. The uniqueness of the proposed technology is expressed in the fact that it is aimed at preparing future specialists for professional activity not only in theoretical, but also in practical and personal aspects. This technology has a significant educational potential, helping students to master not only the expected professional skills, but also positive personal qualities, and stimulates their social activity.

Predicting the promising directions of the presented research, we consider it important to point out the possibility of using the technology of social and emotional learning not only in the process of teaching senior students, which, of course, limits the time of their active immersion in solving emotional and social problems. This technology is appropriate for use at the initial stages of higher education, which is determined by the need to include the socio-cultural context when a teenager goes to higher school and becomes a student. The rationale for this fact has been confirmed by numerous studies by L.M. Apukhina [20].

In summary, we note that in general, training future teachers to work in inclusive education through the technology of social and emotional learning provides students with a wide range of professional competencies, allowing them to train a specialist who is able to solve complex professional problems and is aware of high personal responsibility for decisions made.

\section{References}

1. E.B. Bulavkina, T.V. Timokhina, Problems of modern teacher education, 67-4, 58-61 (2020)

2. V. Gyurova, V.P. Zeleeva, Pedagogical education in a changing world, 202-212 (2017)

3. E.S. Zair-Bek, Letters to the Issue. Offline, 9, 2766 (2019)

4. E.S. Zair-Bek, Izvestia of the Russian State Pedagogical University A.I. Herzen, 185, 15-23 (2017)

5. N.A. Gorokhovskaya, Modern problems of telecommunications, 125-128 (2016)

6. N.V. Simonov, Pedagogical journal, 7 (5 A), 175-181 (2017)

7. D. Goleman, Emotional intelligence: book, p. 478 (Moscow, AST, 1995)

8. E.M. Beam, R. Crowe, M. Cooper, Modern preschool education, 5 (31), 80-84 (2012)

9. O.A. Antropova, Pedagogy and Psychology of Education, 1, 9-15 (2019)

10. L.R. Mukhametgalina, Polish Journal of Science, 27-4 (27), 58-61 (2020)

11. N.B. Golubeva, Modern science: topical problems of theory and practice. Series: Humanities, 3-2, 28-34 (2019)

12. V.P. Musina, Alma mater (Bulletin of the higher school), 6, 22-28 (2015)

13. Yu.V. Shcherbina, E.S. Rakhimova, T.V. Volkodav, Scientific electronic journal Meridian, 3 (37), 270-272 (2020)

14. R.G. Apresyan, Psychology Questions, 1, 29-39 (2019) 
15. A.V. Kiryakova, M.K. Erknalieva, S.V. Zaitseva, A.K. Suleimanova, Problems and prospects for the introduction of innovative telecommunication technologie, 274-282 (2020)

16. L.M. Naymushina, Pedagogy: yesterday, today, tomorrow, 2 (3), 41-48 (2019)

17. M.N. Kozhevnikova, Man and Education, 1 (58), 183-188 (2019)

18. S.V. Shcherbakov, Bulletin of the Omsk State Pedagogical University. Humanities Research, 3 (7), 129-131 (2015)

19. M.A. Ariyan, Language and Culture, 38, 138-151 (2017)

20. L.M. Apukhtina, Regional Bulletin, 11 (50), 63-64 (2020) 